\title{
Narrative review of socioeconomic and racial disparities in the treatment of early stage lung cancer
}

\author{
Nathaniel Evans III ${ }^{1}$, Tyler Grenda ${ }^{1}$, Nkosi H. Alvarez ${ }^{2}$, Olugbenga T. Okusanya ${ }^{1}$ \\ ${ }^{1}$ Division of Thoracic and Esophageal Surgery, Thomas Jefferson University, Philadelphia, PA, USA; ${ }^{2}$ Department of Surgery, Thomas Jefferson \\ University, Philadelphia, PA, USA \\ Contributions: (I) Conception and design: OT Okusanya; (II) Administrative support: OT Okusanya, N Evans; (III) Provision of study materials or \\ patients: All authors; (IV) Collection and assembly of data: All authors; (V) Data analysis and interpretation: All authors; (VI) Manuscript writing: All \\ authors; (VII) Final approval of manuscript: All authors. \\ Correspondence to: Olugbenga T. Okusanya, MD. Thomas Jefferson University, 1025 Walnut St, Suite 605, Philadelphia, PA 19107, USA. \\ Email: Olugbenga.Okusanya@jefferson.edu.
}

\begin{abstract}
Background: To review and discuss the current literature regarding socio-economic and racial disparities in the treatment of early-stage non-small cell lung cancer (NSCLC).

Background: Lung cancer is the most lethal solid organ malignancy in the United States, with the secondhighest incidence of new malignances for both men and women. While overall survival for lung cancer is improving, significant socioeconomic and racial disparities in outcomes for lung cancer persist.

Methods: Narrative review of peer reviewed literature synthesizing findings retrieved from searches of computerized databases, primary article reference lists, authoritative texts and expert options.

Results: The current incidence of lung cancer appears to be similar between White and Black patients. However, Black patients are substantially less likely to receive curative intent surgery. Mitigation strategies do exist to narrow this inequity. Lower socioeconomic status (SES) is associated with a higher incidence of lung cancer, lower utilization of surgery and poorer outcomes after surgery.

Conclusions: Race and SES remain closely linked to outcomes in lung cancer. Outcomes are still worse when controlling for stage and specifically, in early-stage disease, surgical therapy is consistently underused in Black patients and patients of low SES.
\end{abstract}

Keywords: Disparity; inequity; race; lung cancer

Submitted Oct 30, 2020. Accepted for publication Mar 05, 2021.

doi: $10.21037 /$ jtd-20-3181

View this article at: http://dx.doi.org/10.21037/jtd-20-3181

\section{Introduction}

Lung cancer is the most lethal solid organ malignancy in the United with more than 150,000 deaths in 2018 and accounting for approximately $25 \%$ of all cancer deaths (1). While, the majority of lung cancer patients present with metastatic disease, a third of patients present with locoregional disease and approximately fifteen percent present with localized disease only (1). Standard of care treatment for early-stage non-small cell lung cancer (NSCLC) is anatomic lung resection with a multi-station lymph node dissection. Survival after resection of early- stage non-small cell lung cancer (ESNSCLC) can be greater than $85 \%$ at five years (2). For patients who are not surgical candidates, stereotactic ablative radiosurgery (SABR) provides high local control rates and improves survival, although surgical resection remains the standard of care (3).

While overall survival for lung cancer is increasing, significant disparities in outcomes for lung cancer persist. Socioeconomic and racial inequities are pervasive in lung cancer outcomes (4,5). Specifically, patients from lower socioeconomic status (SES) and of Black race have less favorable outcomes compared to those of high SES and non-Hispanic White race (6-9). As these two issues are 
inextricably linked, both will be covered in this narrative review. We present the following article in accordance with the Narrative Review Reporting Checklist (available at: http://dx.doi.org/10.21037/jtd-20-3181).

\section{Methods}

A literature search was conducted via PubMed and Medline databases using the following key words: Lung cancer, racial disparities, socioeconomic, race, Black and lung cancer screening. The inclusion criteria were (I) peer-reviewed academic journals published in English and between the years 1990 and 2020. (II) Research that focused on racial and socio-economic disparities in lung cancer treatment. (III) Research regarding racial and socio-economic differences in tobacco consumption. Manual searches of the reference lists of primary articles found from initial searches were also conducted. Editorials, commentaries and conference abstracts were excluded from the analysis. The impactful and salient articles in the author's opinion were reviewed and synthesized in this review.

\section{Discussion}

\section{Racial inequities}

\section{Background}

The incidence of lung cancer is currently similar between White Americans and Black Americans, with approximately 55 per 100,000 people (1). The rates for all new lung cancer cases have consistently decreased over the last two decades, mainly due to reduced rates of tobacco use. Historically, black men had the highest incidence of lung cancer of any racial and gender group (10). Some have suggested this was due to the high rates of smoking in black men in the southern United States and menthol cigarette smoking in the Black population (11). However, these differences have narrowed in recent years $(12,13)$. Black patients still present with more advanced disease than their White counterparts $(14,15)$. When accounting for the stage at presentation and other factors, Black patients still have lower five-year survival for local disease than their White counterparts. There is also data to suggest that Black patients receiving surgical resection are more likely to die during perioperative period (16).

There are many questions as to the origin of this disparity, as curative lung resection is a major operation with requisite pre-operative functional status and lung function requirements. It has been postulated that disparity in early-stage cancer is due to poor preoperative functional status or lung function, though these assertions have limited support as the complete explanation for the inequity (17). Other more complex issues such as access to care, medical mistrust, disinformation, disparity in testing, disparity in lung function assessment and physician communication all likely play a part $(18,19)$.

\section{Utilization of surgery}

Early reports demonstrate that Black patients were less likely to undergo curative intent surgical therapy (20). Bach et al. used the Surveillance, Epidemiology and End Results (SEER) Medicare database, to analyze patients with Stage I or Stage II NSCLC over the age of 65 for overall survival and the utilization of surgery. The five-year survival for Black and White patients who underwent lung cancer resection was similar at $39 \%$ and $43 \%$, respectively. The five-year survival for patients who did not receive surgery was similar at $4 \%$ and $5 \%$. However, $77 \%$ of White patients underwent surgery, while $64 \%$ of Black patients received surgery. Using hierarchical analyses controlling for age, stage, income, and comorbidities, Black race was still associated with receiving less surgery than White race. Thus, they concluded that race as a sole factor associated with the lower utilization of surgery and the disparity in overall survival between Black and White patients.

A more recent study by Dalwadi et al. used the SEER database in a more modern sample to look at the utilization of surgery by race (21). They analyzed patients aged 60 and over between 2004 and 2012 with Stage I and Stage II NSCLC. They report that Black patients received surgery at a 58 percent rate compared to 67 percent of White patients and had a two-year lung cancer-specific survival of 76 percent compared to 79 percent in White patients. When adjusting for stage, age, and treatment, the difference in survival was no longer significant.

Soneji et al. analyzed surgery utilization rates in earlystage cancer patients by race (9). Black patients were not recommended surgery at a $34 \%$ rate, while White and Asian patients had surgery not recommended at a rate of $24 \%$. Overall survival for Black patients, including all causes, was lower for Black patients. When controlling for the receipt of surgery in patients with early-stage lung cancer, there was still worse overall survival for Black patients. This was found to be due to higher rates of death from other competing causes, including heart and kidney disease. 
Our group recently chose to investigate this topic using the National Cancer Database (NCDB). We analyzed the utilization of local therapy (surgery and radiation) therapy (4). We found a similar trend with White patients receiving significantly more surgery than Black patients in our sample from 2004 to 2015 (67\% vs. $60 \%, \mathrm{P}<0.001$ ). We also found that the rates of surgery for both Black and White patients improved dramatically from 2004 to 2015, with White patients increasing from $57 \%$ to $65 \%$ and Black patients increasing from $44 \%$ to $62 \%$. When adjusting for the receipt of surgery, the survival difference between Black and White patients disappeared. In the most recent sample, Black patients who received surgery had improved survival compared to White patients, likely due to their younger age at diagnosis.

\section{Mitigation}

As the studies above have clearly shown, there is a persistent inequity in the utilization of surgery between Black and White patients. Some groups have looked to determine the mechanism of the development of these inequities and how to mitigate them. Cykert et al. interviewed patients with newly diagnosed resectable lung cancer and asked them what factors influenced their decision to undergo or not undergo surgical resection (22). They found the same disparity in the utilization of surgery in Black patients as others found historically. Both White and Black patients' poor perception of patientphysician communication and negative perception of one-year survival after surgery were associated with deferring surgical therapy. Black patients with two or more comorbidities and no regular source of healthcare were very likely to defer surgery (22).

Multiple studies have shown that Black patients have complex views on the receipt of surgery. Studies have shown that poor physician-patient communication, misconceptions about cancer biology, and low trust all result in Black patients not choosing surgery when it is offered $(23,24)$. A multi-site interventional study looked at eliminating the gap in utilizing surgery by using a three-pronged approach (25). The intervention was a real-time warning in the electronic medical record, feedback to the providers about the outcomes of early-stage lung cancer by race, and the utilization of a nurse navigator to manage the warning system. The intervention raised the level of local therapy for both races and equalized them from pre-intervention levels (25).

\section{Socioeconomic disparities}

\section{Background}

Socioeconomic factors are broadly defined as a combination of income, education, area of residence, and insurance status. The Black population in America experiences a significantly lower SES than the White population in America. Specifically, Black people have lower levels of wealth, education and are more likely than White patients to live in urban areas (26-28). These inequities stem from the history of slavery, Jim Crow, and systemic racism in America.

Socioeconomic disparities in outcomes for all cancers have been widely noted (29). Specifically, for lung cancer, it has been demonstrated that the incidence of lung cancer increases as patients have lower SES $(8,30)$. Based on race, patients of lower SES present with more advanced disease than those with higher status. Low SES is tied to tobacco use and is partially thought to be the driving force behind the high incidence of cancer in this group. However, environmental factors and exposures to other known carcinogens are likely to contribute $(31,32)$. Some reports indicate that poor SES make it $70 \%$ more likely for men and 50\% more likely for women to develop lung cancer (31).

\section{Detection and management}

Recently the National Lung Cancer Screening Trial and the NELSON trial in Europe have demonstrated improved lung cancer-specific survival for high-risk patients screened with CT scans $(33,34)$. This benefit is most pronounced in women and racial minority patients. As in other areas in cancer care, disparities in screening exist based on SES (35). Specifically, uninsured patients are $72 \%$ less likely to get screened than insured patients. For patients with detected cancers, SES plays a role in their early management. Population-level data indicates that higher SES is associated with a higher likelihood of receiving the following indicated interventions: a brain MRI, lung resection, palliative radiation, and adjuvant chemotherapy. Lower SES is also closely associated with not receiving NCCN guidelineconcordant care $(36,37)$.

For ESNSCLC, the standard of care is anatomic lung resection with systematic lymph node sampling. Lower SES has not been associated with higher rates of refusal when surgery is offered (38). However, lower income and lower SES was associated with not receiving surgery or any local 
therapy in several multivariable analyzes using large datasets $(4,39)$. These inequities in these studies persisted even when controlling for race. A recent meta-analysis of 46 studies showed that lower SES had an OR of 0.68 as compared to the highest SES for the receipt of surgery (40).

\section{Outcomes}

Further compounding the inequities of SES and lung cancer are the outcomes of lower SES patients after surgery. First, even though patients with lower SES are diagnosed at a younger age, they are far more likely to suffer lung cancer mortality even when adjusting for stage at diagnosis (8). Even after pulmonary resection, lower SES was still associated with lower overall survival (41). Lower SES, specifically income and insurance status, on analysis of the National Cancer Database is associated with hospital readmission after surgical resection and readmission after surgical resection has been associated with decreased longterm survival $(42,43)$. For patients who are found to have locoregional disease, it has been shown they are less likely to receive chemotherapy in the adjuvant setting, which improves survival $(41,44,45)$.

\section{Conclusions}

Race and SES remain closely linked to outcomes in lung cancer. It is likely that there many contributing factors as to why black patients are less likely to receive surgical therapy including racism, medical mistrust, suboptimal communication and nihilism. Though SES appears to the tied to the overall incidence of cancer, the incidence of lung cancer currently does not correlate with race alone. There seems to be a bias for patients to present with more advanced disease for both low SES and Black race. However, outcomes are still worse when controlling for stage. Specifically, in early-stage disease, surgical therapy is consistently underused in Black patients and patients of low SES. Our review does have limitations since we may not have included all the relevant published literature due to the limited electronic databases examined and the language criterion. However, our review attempts to summarize the empirical evidence concerning the disparities in the delivery of standard of care lung cancer treatment to patients of both low SES and Black race, and serves as a basis for future efforts to understand and attempt to remedy these disparities.

\section{Acknowledgments}

Funding: None.

\section{Footnote}

Provenance and Peer Review: This article was commissioned by the Guest Editors (Virginia Litle and Kei Suzuki) for the series "Socioeconomic Disparities in the Treatment of Thoracic Malignancies" published in Fournal of Thoracic Disease. The article has undergone external peer review.

Reporting Checklist: The authors have completed the Narrative Review Reporting Checklist. Available at http:// dx.doi.org/10.21037/jtd-20-3181

Peer Review File: Available at http://dx.doi.org/10.21037/jtd20-3181

Conflicts of Interest: All authors have completed the ICMJE uniform disclosure form (available at http://dx.doi. org/10.21037/jtd-20-3181). The series "Socioeconomic Disparities in the Treatment of Thoracic Malignancies" was commissioned by the editorial office without any funding or sponsorship. The authors have no other conflicts of interest to declare.

Ethical Statement: The authors are accountable for all aspects of the work in ensuring that questions related to the accuracy or integrity of any part of the work are appropriately investigated and resolved.

Open Access Statement: This is an Open Access article distributed in accordance with the Creative Commons Attribution-NonCommercial-NoDerivs 4.0 International License (CC BY-NC-ND 4.0), which permits the noncommercial replication and distribution of the article with the strict proviso that no changes or edits are made and the original work is properly cited (including links to both the formal publication through the relevant DOI and the license). See: https://creativecommons.org/licenses/by-nc-nd/4.0/.

\section{References}

1. Siegel RL, Miller KD, Jemal A. Cancer statistics, 2020. CA Cancer J Clin 2020;70:7-30.

2. Goldstraw P, Chansky K, Crowley J, et al. The IASLC 
lung cancer staging project: Proposals for revision of the TNM stage groupings in the forthcoming (eighth) edition of the TNM classification for lung cancer. J Thorac Oncol 2016;11:39-51.

3. Ball D, Mai GT, Vinod S, et al. Stereotactic ablative radiotherapy versus standard radiotherapy in stage 1 nonsmall-cell lung cancer (TROG 09.02 CHISEL): A phase 3 , open-label, randomised controlled trial. Lancet Oncol 2019;20:494-503.

4. Lutfi W, Martinez-Meehan D, Sultan I, et al. Racial disparities in local therapy for early stage non-small-cell lung cancer. J Surg Oncol 2020;122:1815-20.

5. Williams CD, Salama JK, Moghanaki D, et al. Impact of race on treatment and survival among U.S. veterans with early-stage lung cancer. J Thorac Oncol 2016;11:1672-81.

6. Teng AM, Atkinson J, Disney G, et al. Changing socioeconomic inequalities in cancer incidence and mortality: Cohort study with 54 million person-years follow-up 1981-2011. Int J Cancer 2017;140:1306-16.

7. Islami F, Kahn AR, Bickell NA, et al. Disentangling the effects of race/ethnicity and socioeconomic status of neighborhood in cancer stage distribution in new york city. Cancer Causes Control 2013;24:1069-78.

8. Yang R, Cheung MC, Byrne MM, et al. Do racial or socioeconomic disparities exist in lung cancer treatment? Cancer 2010;116:2437-47.

9. Soneji S, Tanner NT, Silvestri GA, et al. Racial and ethnic disparities in early-stage lung cancer survival. Chest 2017;152:587-97.

10. DeSantis CE, Miller KD, Goding Sauer A, et al. Cancer statistics for african americans, 2019. CA Cancer J Clin 2019;69:211-33.

11. Park ER, Japuntich SJ, Traeger L, et al. Disparities between blacks and whites in tobacco and lung cancer treatment. Oncologist 2011;16:1428-34.

12. Jemal A, Miller KD, Sauer AG, et al. Changes in blackwhite difference in lung cancer incidence among young adults. JNCI Cancer Spectr 2020;4:pkaa055.

13. Haiman CA, Stram DO, Wilkens LR, et al. Ethnic and racial differences in the smoking-related risk of lung cancer. N Engl J Med 2006;354:333-42.

14. Sineshaw HM, Sahar L, Osarogiagbon RU, et al. Countylevel variations in receipt of surgery for early-stage non-small cell lung cancer in the united states. Chest 2020;157:212-22.

15. Schwartz KL, Crossley-May H, Vigneau FD, et al. Race, socioeconomic status and stage at diagnosis for five common malignancies. Cancer Causes Control
2003;14:761-6.

16. Harrison MA, Hegarty SE, Keith SW, et al. Racial disparity in in-hospital mortality after lobectomy for lung cancer. Am J Surg 2015;209:652-8.

17. Williams CD, Stechuchak KM, Zullig LL, et al. Influence of comorbidity on racial differences in receipt of surgery among US veterans with early-stage non-small-cell lung cancer. J Clin Oncol 2013;31:475-81.

18. Berger M, Lund MJ, Brawley OW. Racial disparities in lung cancer. Curr Probl Cancer 2007;31:202-10.

19. Hankinson JL, Odencrantz JR, Fedan KB. Spirometric reference values from a sample of the general U.S. population. Am J Respir Crit Care Med 1999;159:179-87.

20. Ezer N, Mhango G, Bagiella E, et al. Racial disparities in resection of early stage non-small cell lung cancer: Variability among surgeons. Med Care 2020;58:392-8.

21. Dalwadi SM, Lewis GD, Bernicker EH, et al. Disparities in the treatment and outcome of stage I Non-Small-cell lung cancer in the 21st century. Clinical Lung Cancer 2019;20:194-200.

22. Cykert S, Dilworth-Anderson P, Monroe MH, et al. Factors associated with decisions to undergo surgery among patients with newly diagnosed early-stage lung cancer. JAMA 2010;303:2368-76.

23. Margolis ML, Christie JD, Silvestri GA, et al. Racial differences pertaining to a belief about lung cancer surgery: Results of a multicenter survey. Ann Intern Med 2003;139:558-63.

24. Gordon HS, Street RL Jr, Sharf BF, et al. Racial differences in trust and lung cancer patients' perceptions of physician communication. J Clin Oncol 2006;24:904-9.

25. Cykert S, Eng E, Manning MA, et al. A multi-faceted intervention aimed at black-white disparities in the treatment of early stage cancers: The ACCURE pragmatic quality improvement trial. J Natl Med Assoc 2020;112:468-77.

26. Ostrove JM, Feldman P. Education, income, wealth, and health among whites and african americans. Ann N Y Acad Sci 1999;896:335-7.

27. Yeung WJ, Conley D. Black-white achievement gap and family wealth. Child Dev 2008;79:303-24.

28. Pfeffer FT, Killewald A. Intergenerational wealth mobility and racial inequality. Socius 2019. doi: 10.1177/2378023119831799.

29. Singh GK, Jemal A. Socioeconomic and racial/ethnic disparities in cancer mortality, incidence, and survival in the united states, 1950-2014: Over six decades of changing patterns and widening inequalities. J Environ Public 
Health 2017;2017:2819372.

30. Hastert TA, Beresford SA, Sheppard L, et al. Disparities in cancer incidence and mortality by area-level socioeconomic status: A multilevel analysis. J Epidemiol Community Health 2015;69:168-76.

31. Mao Y, Hu J, Ugnat AM, et al. Socioeconomic status and lung cancer risk in canada. Int J Epidemiol 2001;30:809-17.

32. van Loon AJ, Goldbohm RA, Kant IJ, et al. Socioeconomic status and lung cancer incidence in men in the netherlands: Is there a role for occupational exposure? J Epidemiol Community Health 1997;51:24-9.

33. de Koning HJ, van der Aalst CM, de Jong PA, et al. Reduced lung-cancer mortality with volume CT screening in a randomized trial. N Engl J Med 2020;382:503-13.

34. National Lung Screening Trial Research Team, Aberle DR, Adams AM, et al. Reduced lung-cancer mortality with low-dose computed tomographic screening. N Engl J Med 2011;365:395-409.

35. Zgodic A, Zahnd WE, Miller DP Jr, et al. Predictors of lung cancer screening utilization in a population-based survey. J Am Coll Radiol 2020;17:1591-601.

36. Shah M, Parmar A, Chan KKW. Socioeconomic disparity trends in diagnostic imaging, treatments, and survival for non-small cell lung cancer 2007-2016. Cancer Med 2020;9:3407-16.

37. Obrochta CA, Murphy JD, Nara A, et al. Disparities in receipt of guideline concordant treatment for early-stage non-small cell lung cancer (NSCLC) patients in california. JCO 2019;37:160.

38. Mehta RS, Lenzner D, Argiris A. Race and health

Cite this article as: Evans N 3rd, Grenda T, Alvarez NH, Okusanya OT. Narrative review of socioeconomic and racial disparities in the treatment of early stage lung cancer. J Thorac Dis 2021;13(6):3758-3763. doi: 10.21037/jtd-20-3181 disparities in patient refusal of surgery for early-stage nonsmall cell lung cancer: A SEER cohort study. Ann Surg Oncol 2012;19:722-7.

39. Kærgaard Starr L, Osler M, Steding-Jessen M, et al. Socioeconomic position and surgery for early-stage nonsmall-cell lung cancer: A population-based study in denmark. Lung Cancer 2013;79:262-9.

40. Forrest LF, Adams J, Wareham H, et al. Socioeconomic inequalities in lung cancer treatment: Systematic review and meta-analysis. PLoS Med 2013;10:e1001376.

41. Khullar OV, Gillespie T, Nickleach DC, et al. Socioeconomic risk factors for long-term mortality after pulmonary resection for lung cancer: An analysis of more than 90,000 patients from the national cancer data base. J Am Coll Surg 2015;220:156, 168.e4.

42. Medbery RL, Gillespie TW, Liu Y, et al. Socioeconomic factors are associated with readmission after lobectomy for early stage lung cancer. Ann Thorac Surg 2016;102:1660-7.

43. Hu Y, McMurry TL, Isbell JM, et al. Readmission after lung cancer resection is associated with a 6-fold increase in 90-day postoperative mortality. J Thorac Cardiovasc Surg 2014;148:2261, 2267.e1.

44. Farrow NE, An SJ, Speicher PJ, et al. Disparities in guideline-concordant treatment for node-positive, non-small cell lung cancer following surgery. J Thorac Cardiovasc Surg 2020;160:261, 271.e1.

45. Blom EF, Ten Haaf K, Arenberg DA, et al. Disparities in receiving guideline-concordant treatment for lung cancer in the united states. Ann Am Thorac Soc 2020;17:186-94. 